\title{
CORONA-VIRUS CRISIS AND EFFECTIVE CHANGE MANAGEMENT:ETHICAL IMPLICATIONS
}

\author{
Evaggelia Kiosi ${ }^{1 *}$, \\ Konstantinos M. Karyotakis², \\ Kyriakos Dimitriou ${ }^{3}$
}

\author{
${ }^{1}$ National and Kapodestrian \\ University of Athens \& University \\ of Peloponnese, \\ Kalamata, Greece
}

${ }^{2}$ Technical University of Crete, Chania, Greece

3 University of Piraeus, Athens, Greece

\begin{abstract}
:
Organizations today are bound to make frequent and substantial changes to the way they operate in a rapidly changing environment. Organizations anticipate, design for, and capitalize on change adapting concepts such as external and internal (insider) threat and combining strategy, research, and science in order to innovate for the emerging and unexpected. This contribution focuses on the ethical implications concerning the effective change management in organizations, due to Corona-virus crisis focusing on the new ethical dilemmas that modern leadership has to face suddenly. In a further approach, and through the philosophical view of ethics, the paper explores certain human behavior - concerning leaders and employees - that has a strong impact on successful implementation of organizational change. The common point of reference in the stated approaches is the human element, as an influencing factor, but also as a subject to change.
\end{abstract}

\section{Keywords:}

change, corona-virus, ethics, insider threat, leadership.

\section{INTRODUCTION}

'This is a joke...something strange is happening but it will pass...nothing is happening...things like that happen...' (Camus, 2001). Albert Camus's 'The Plague' deals with human nature and fate and represents how the world deals with the philosophical notion of the 'absurd'. 'But the whole world is facing the same problem... - Exactly...now we are like the whole world...' (Camus, 2001). And that is the equivocal character of a pandemic ${ }^{1}$.

Through the centuries, humankind has experienced many 'plagues', but they seemed unprepared in all cases. History has to offer experiences like the Plague of Athens (430-426 BC), the Black Death (1331-1353), the Spanish flu (1918-1920), and the 2014 Ebola outbreak that infected and provoked the deaths of millions of people around the world.

Today, Covid-19 is a fast-moving crisis ${ }^{2}$ that has disrupted every system and organization in the world. In fact, the impact of this crisis is multidimensional on the following: public health, the economy, politics, and everyday human life. The current pandemic has put into consideration a new dimension of the notion 'insider threat', a malicious threat to an organization that comes from people within it.

Correspondence:

Evaggelia Kiosi

e-mail:

evaggeliakiosi@yahoo.gr
1 The word derives from Greek words $\pi \tilde{\alpha} v$ (pan, all) and $\delta \tilde{\eta} \mu \circ \varsigma$ (demos, people) and means a disease that has spread across a large region or worldwide.

2 The term 'crisis' derives from the Greek word 'kpion' (crisis), and refers to the concepts of 'judgment' and 'decision' (Benaben et al., 2016). 
Indeed, the outbreak has the hallmarks of a 'landscape scale' crisis:

An unexpected event or sequence of events of enormous scale and overwhelming speed, resulting in a high degree of uncertainty that gives rise to disorientation, a feeling of lost control, and strong emotional disturbance

(D’Auria \& De Smet, 2020).

The peculiarity of a crisis situations lies in the fact that they are characterized by low readiness and high urgency. However, there is an urgent need for change; otherwise the consequences can be fatal. The changes should be immediate and targeted, adding reliability, honesty and specialization (Armenakis et al., 1993).

Covid-19 is progressing and it is a 'revolt' (fast moving event) that is creating a 'release' (breakdown) period, which will eventually lead to 'reorganization'. New ideas, structures, and solutions might artificially 'conserve' old systems by resorting to new strategies (Zaidi, 2019).

There has never been a greater challenge for leaders of this generation (von Eck, 2020). As it has been argued 'leadership is the capacity of a human community to shape its future' (Razzetti, 2020).

In times of crisis all stakeholders need guidance by capable leaders. It is crucial for leaders to focus on the broader societal environment, align their operational practices, and treat stakeholders as humans (Winkler Titus, 2020).

This contribution focuses on the ethical implications concerning the effective change management in organizations, which must be targeted and time sensitive due to Corona-virus crisis; focusing on the new ethical dilemmas that modern leadership suddenly has to face.
In a further approach, and through the philosophical view of ethics, the paper explores certain human behavior - concerning leaders and employees - that has a strong impact on successful implementation of organizational change. The common point of reference in the stated approaches is the human element, as an influencing factor, but also as a subject to change.

\section{LITERATURE REVIEW}

\subsection{Facing Covid-19: Recognize}

'The spread of the pandemic has brought to the fore the need for business leaders to recognize the crucial interdependencies between business and its environmental, social, and governance context' (Hamann, 2020).

It has been argued that three major drives will influence the trajectory of the pandemic (Morrison \& Carroll, 2020):
a. the virus itself,
b. government tools,
c. technology.

Changes can affect structure (functional change), process, values or power distribution. When changes are made to all those sectors, they refer to a systemic approach change (Cao et al, 2000). Another categorization of changes (Cao et al., 2000, 187) is described in Table 1.

Table 1. Classification of Organizational Change

\begin{tabular}{ll}
\hline Category of Organizational Change & Reference (s) \\
\hline Strategic and non-strategic & Pettigrew (1987), Rajagopalan and Spreitzer (1997) \\
\hline $\begin{array}{l}\text { Incremental and radical } \\
\text { Burnes (1992), Johnson and Scholes (1993), Goodstein } \\
\text { and Warner (1997) }\end{array}$ \\
\hline Incremental and 'quantum' & Greenwood and Hinings (1993) \\
\hline Changes of identity, co-ordination and control & Kanter et al. (1992) \\
\hline $\begin{array}{l}\text { Human-centered classification of change at individual, } \\
\text { group, inter-group or organization level }\end{array}$ & Burnes (1992) \\
\hline $\begin{array}{l}\text { Planned change and emergent change } \\
\begin{array}{l}\text { Change in terms of scale (from incremental to radical) } \\
\text { and centrality (from peripheral to core) to the primary } \\
\text { task of the organization }\end{array}\end{array}$ & Buchanan and Boddy (1992) \\
\hline
\end{tabular}


Table 2 depicts the nomenclature of organizational change. Scheduled or unpredictable events can lead to the urgent need for structural measures regarding the redesigning of strategies, structure, processes and culture of an organization. The role of individuals in the continuous and dynamic process of organizational change should not be underestimated.
On the contrary, it should be widely understood that individuals constitute the backbone and the driving force in this procedure.

After all, an organization may announce change, but people are the ones who are called upon to implement those decisions that are expected to bring this change.

Table 2. The focal point of the humankind in the process of organization change.

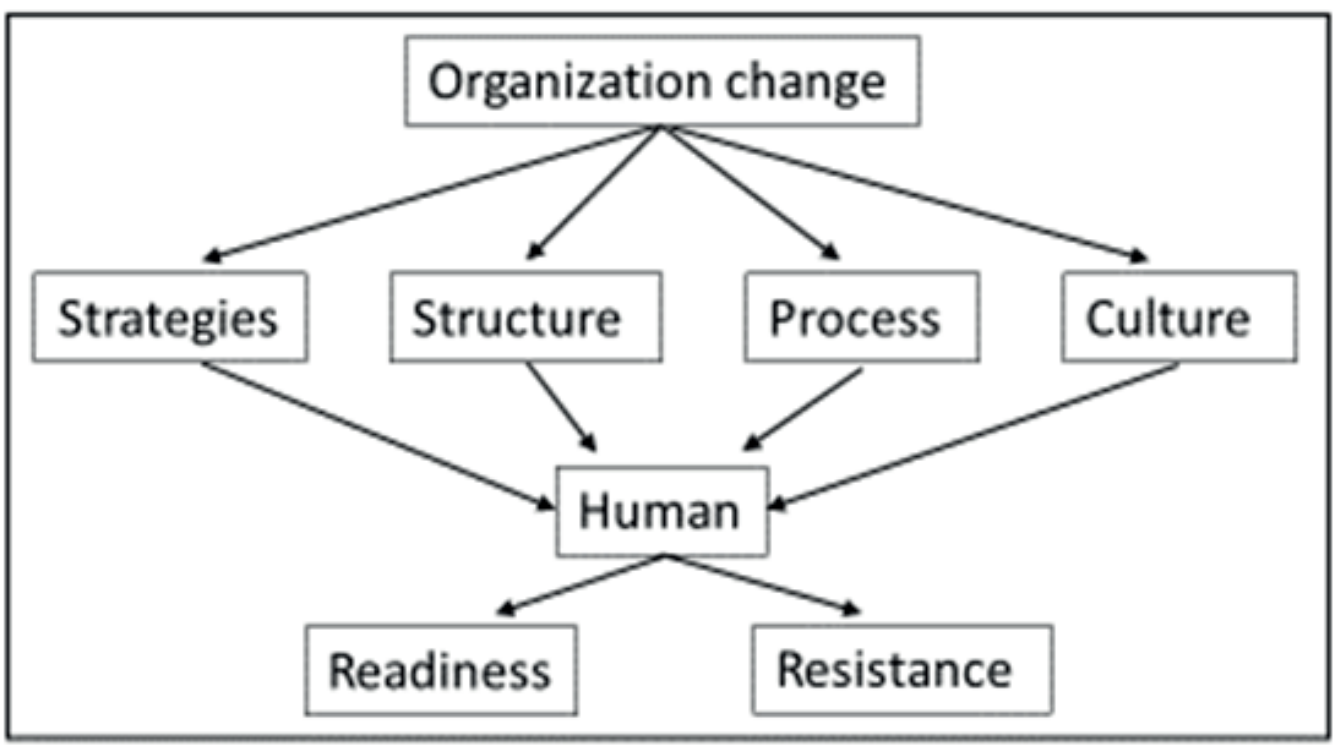

Modified by Shah et al. (2017, p. 367).

The behavior and reactions of human capital can support a change (when there is a high degree of readiness to change) or even stimulate it (when there is a high degree of resistance to change).

In change management, the crucial point is untwisting the interconnection of the individual parts, the way that the change in one of them affects the others and the whole system, as well as how the harmony is achieved (Duck, 1993).

Bibliographic review of Shah et al. (2017) of the workplace identifies workplace and individual factors that affect readiness to change.

Workplace factors include: active and passive job, appropriateness, change efficacy, communication, decision latitude, discrepancy, flexible policies and procedures, job demands, job knowledge and skills, logistic and system support, management and leadership relationships, organizational commitment, organizational culture, perceived organizational support, personal valence, social relations in the workplace, social support, wellness and justice.

Individual factors include: adaptability, autonomy, beliefs, demography, depression, emotional exhaustion, general attitude, job related attitude, intention to quit, self-efficacy, job satisfaction, participation, personal resilience, rebelliousness, skills variety, supervisory support, team work, trust (in peers, management, and senior leaders), turnover, work irritation, affective commitment, personality and training.

On the other hand, factors regarding resistance to change include: emotion, ineffective communication, insufficient planning, and lack of readiness, leadership failure, non-satisfaction, politics and uncertainty.

People are the most important asset in any business organization, while in the context of competition between them, the quality of employees is also an advantage. Nevertheless, people have their advantages and disadvantages, since each of us is different. We all have feelings, stress and make mistakes. An internal threat, therefore, occurs when these factors cause an employee to, intentionally or unintentionally, endanger valuable information, material, people, or facilities.

The COVID-19 pandemic is clearly an important factor in increasing the risk of negligence or malicious confidential information on critical assets and data. When combined with huge financial uncertainty, the loss of critical assets including research and development, proprietary information and critical equipment, it can impede an organization's recovery. The threat of internal threats is often overlooked, but it can be so detrimental to the employer that it can lead to the collapse of a business. It can be intentional (in the form of a disgruntled employee, 
or accidental (workers causing unintentional harm, for example, by clicking on a phishing fraud link) for three main reasons:

a. Working from home environment. Staff cannot be closely monitored while being at home, making the risk of an unintentional accident higher.

b. The increase of opportunistic factors. In times like these, hackers are a big problem as they take advantage of situations and their attacks increase rapidly.

c. Employee morale. Employees may feel more distracted from the workplace as they are not physically present in the office (this increases the longer the quarantine regime lasts). They are also concerned about job security, especially if pay cuts have been imposed, or worse if layoffs are taking place. This can increase the intentional threat' where staff may be more motivated to harm their employer.

\subsection{Facing Covid-19: Response}

Since a crisis is ruled by unfamiliarity and uncertainty, effective responses are largely improvised (Howitt \& Herman, 2009).

In general, in cases of crisis, three types of leadership are indicated (VanWart \& Kapucu, 2011):

a. Need for calm but 'strong' leadership. The leader must be able to make valid and timely decisions, despite the stressful and chaotic situations he may experience, avoiding showing panic, the existence of which can be even worse than the very criticality of the situation. Perceived competence needs: self-confidence, willingness to assume responsibility, motivating, articulating vision and mission, resilience, communication skills.

b. Need for decisions that require excellent analytic skills under strict time constraints and resource constraints. Often, there is no time for system alteration and adaptation or long-term enhancements. In addition, leaders need to be flexible and adapt to developments and new data. Perceived competence needs: decision making, analytic skills, decisiveness, flexibility, delegating.

c. There is a need for 'strong' leadership style as well as for more 'routine' managerial tactics and restructuring. There must be flexibility of individual teams, greater delegation, and assurance of leaders that teams remain engaged, even in cases of exhaustion. Cases of expansion of parties involved should also be considered. Perceived competence needs: operations planning, team building, networking and partnering, social skills.

However, no system can be implemented effectively and successfully, no matter how well designed, if people are not convinced of its usefulness and are reluctant to use it.
Oral and written speeches, declarations, personal communication and presence etc. are required in order to achieve convincing communication. In this way, emphasis should be given to human capital (and its reactions), which is dynamically involved and influences the outcome of the change process.

It is important to cultivate a culture of readiness and maturity, where mutual efforts will be made. This mentality must be nurtured in such a way that it is possessed by an excellent channel of communication, respect, appreciation and commitment between all parties involved (Karyotakis \& Moustakis, 2014), as well as limiting phenomena of resistance to change (Karyotakis \& Moustakis, 2016). Rational management of external information and active participation certainly add value to crisis situations, and that is what is required. However, due to the time constraints that exist, it is difficult to achieve their optimal utilization.

VanWart \& Kapucu (2011) highlight, among other things, the importance and effectiveness of technical and political communication in cases of crisis. Note that technical communication is required to be precise, concise and confirmed. On the other hand, in terms of communication at the political level, as a manager typically notes in their research, a leader should be able to formulate the message in the right way and become a part of it, both to the immediate recipients and to the general public.

Regarding the constantly evolving notion of insider threats, it is of great value taking precautionary measures, improving existing policies and implementing new ones to better protect critical assets in the face of emerging threats:

a. policies - implementing clear policies that will be understood by all;

b. education - providing all employees with regular mandatory training e.g. on detecting phishing fraud, how to report suspicious activity and how to keep data secure;

c. contact - informing employees about the risk of internal threats that must be channeled by management to employees. Regular employee-management contact can help staff feel supported and supported by it and increases the likelihood of reporting any suspicious activity;

d. regular review - re-evaluation - it is important that risk and data management is an ongoing obligation. Training and communication should be regular and policies should be reviewed regularly to ensure that they are up to date and still followed by staff members. 


\subsection{Facing Covid-19: Ethical Implications}

It has been argued that due to Covid-19 crisis 'we need a leadership revolution. To get rid of leadership labels and start building a new model to thrive in this new normal. Developing meta-skills is critical to improving our ability to lead effectively' (Razzetti, 2020):

a. Increased Self-Awareness;

b. Being Empathetic;

c. Promote Psychological Safety;

d. Embrace Intellectual Humility;

e. Collective Leadership;

f. Balancing candor with optimism.

On the other hand, as Kaptein underlines:

The three important yardsticks of work are the three 'Es' (Kaptein 2019, 29):

a. Effectiveness (the extent to which the goals are achieved).

b. Efficiency (the extent to which the goals are achieved with the least possible effort).

c. Ethics (the extent to which the goals and means are morally good).

It has been argued that without the study of ethics, the understanding of leadership is incomplete: Ethical values always take part in leadership, regardless of whether leaders are clearly aware of the fact. In addition, it has been argued that leaders recognize their responsibility as the main guardian of their group's values (Demetroules, 2015).

Regarding the definition of 'ethics':

Ethics is about what drives you (compassion), who you are (integrity), how you appear (honesty), how you act (trustworthiness), how you treat others (equality) and what you achieve (sustainability) (Kaptein 2019, 153).

A recently conducted research by the Ethics Institute has pointed out that the ethical culture of an organization should combine (Van Vuuren \& Vorster, 2020):

a. ethics accountability and responsibility;

b. the commitment of non-managerial employees, middle management and leadership (senior management) commitment to ethics;

c. ethics talk;

d. the ethical treatment of people;

e. ethics awareness in the organization.

In situations like the Covid-19 crisis, Rossouw suggests moral imagination not only to deal with ethical dilemmas, but also to try and prevent moral dilemmas from occurring in the first place:
Leaders in organizations cannot rely on ready-made answers that can be downloaded from a platform, or on algorithms that can solve the tough choices on their behalf. It requires leaders to go through the process of consulting with others, but also consulting their own conscience and values. It demands moral reasoning to come up with the best possible solution, while still carrying the weight of the knowledge that there will be collateral damage (Rossouw, 2020).

\section{CONCLUSION}

'The world will never be the same again after Covid-19. The Corona-virus pandemic will change the world order forever' (Kissinger, 2020).

Pandemics change the trajectory of history by transforming societies, organizations, people, but also norms, and governing structures.

Visions of the future need to account for reframing in three areas: capabilities, operations, relationships, and how they interact with each other in order to help humanity prepare for the challenges ahead.

It has been argued that 'crisis always has the potential of bringing out the best and the worst in human beings. This is not only true of individuals, but also of organizations' (Rossouw, 2020).

The role of individuals in the continuous and dynamic process of organizational change is crucial. Emphasis should be given on human capital, which is dynamically involved and influences the outcome of any change process.

The Covid-19 pandemic is projected to increase the incidence of internal threats to organizations and businesses. This prediction combined with social inequalities, poverty and unemployment poses new challenges in the context of effective change management.

Workplace and individual factors that affect readiness for change regard effective communication and leadership, as well as ethical culture and awareness in organizations.

The current crisis 'calls for the best in humanity with ethical principles as our compasses' (Azulay, 2020).

Leaders of states and organizations therefore need to adapt their policies and practices paying attention that all stakeholders are simply seen as humans. Besides the evolution of technology and the new types of threat it challenges, the nature of humanity still alleges that sustainability can be realized only through respect and ethical treatment of the human element.

Ethics is about asking the right questions. It is critical to acknowledge the worth of moral reasoning and ethical leadership as a factor of effective change management.

After all, 'maybe, it is still too soon to predict the implications of the corona pandemic. But it is never too soon to think about these issues' (Levy, 2020). 


\section{LITERARURE}

\section{Literature in Greek}

Camus, A. (2001). The Plague (Karakitsou-Douze, N. -Kasabaloglou-Roblen, M. Tr). Athens: Kastaniotis.

Demetroules, D. (LtGen ret). (2015). Military Ethos and Leadership. Athens: Hellenic National Defense General Staff.

\section{Literature in English}

Azulay, A. UNESCO Director-General. UNESCO's International Bioethics Committee (IBC) and World Commission on the Ethics of Scientific Knowledge and Technology (COMEST) Joint Statement to Governments and Policy Makers :https://lnkd.in/eBR5ASQ

Benaben, F. \&Lauras, M. \& Truptil, S. \& Salatge, N. (2016). 'A Metamodel for Knowledge Management in Crisis Management'. $201649^{\text {th }}$ Hawaii International Conference on System Sciences (HICSS).

Buchanan, D. \&Boddy, D. (1992). The Expertise of the Change Agent: Public Performance and Backstage Activity. PrenticeHall, Hemel Hempstead.

Burnes, B. (1992). Managing Change. London: Pitman.

Cao, G. \& Clarke, S. \& Lehaney, B. (2000). 'A Systemic View of Organizational Change and TQM. The TQM Magazine, 2(3), 186-193.

Collins, T. \& Fussell, C. \& Gen. McChrystal, S. \& Silverman, D. (2015). Team of Teams: New Rules of Engagement for a Complex World, first edition, New York, NY: Portfolio/ Penguin, 2015.

D’Auria, G. \&De Smet, A. (2020). 'Leadership in a Crisis: Responding to the Corona-virus

Outbreak and Future Challenges', March 2020: https://www. mckinsey.com/business-functions/organization/ourinsights/leadership-in-a-crisis-responding-to-the-coronavirus-outbreak-and-future-challenges?cid=soc-web

Duck, J.D. (1993). Managing Change: The Art of Balancing'. Harvard Business Review, 71(6),109-118.

Goodson, S. \& Demos, A. \&Dhanaraj, C. (2020). 'Shift Your Organization from Panic to Purpose'. April 27, 2020. Harvard Business Review:https://hbr.org/2020/04/ shift-your-organization-from-panic-to-purpose?utm source=linkedin\&utm_medium =social\&utm campaign $=\mathrm{hbr}$

Goodstein, L. \& Warner, B. (1997). 'Creating Successful Organizational Change' in:Carnall, C. (Ed). Strategic Change. Oxford: Butterworth-Heinemann, pp. 159-173.

Greenwood, R. \&Hinings, C.R. (1993). 'Understanding Strategic Change: The Contribution of Archetypes'. Academy of Management Journal, 36(5), 1052-81.

Hamann, R. (2020). 'Coronavirus will have long-term impacts for business leaders. Here are the top 5'. Apr 062020 in: fin24:https://www.fin24.com/Opinion/analysis-coronavirus-will-have-long-term-impacts-for-business-leadershere-are-the-top-5-20200405

Howitt, A. \& Herman, L. B. (eds). (2009). Managing Crises: Responses to Large-Scale Emergencies, first edition, Washington, DC: CQ Press.

Johnson, G. \&Scholes, K. (1993). Exploring Corporate Strategy. Prentice-Hall, New York.
Kanter, R.S., Stein, B. \&Jick, T.D. (1992).The Challenge of Organisational Change. The Free Press, New York.

Kaptein, M. (2019). Maxims. A Collection for Work: https://www. slideshare.net/MuelKaptein/maxims-a-collection-for-work

Karyotakis, K. M., \&Moustakis, V. S. (2014). 'Reinvention of the Public Sector: Total Quality Management and Change Management'. Singidunum Journal of Applied Sciences, 11(2), 30-44.

Karyotakis, K. M., \&Moustakis, V. S. (2016). 'Organizational Factors, Organizational Culture, Job Satisfaction and Entrepreneurial Orientation in Public Administration'. The European Journal of Applied Economics, 13(1), 47-59.

Kissinger, H. (2020). 05 April 2020: https://www.capital.gr/ diethni/3443632/xenri-kisingker-i-pandimia-tou-koronoiou-tha-allaxei-gia-panta-tin-pagkosmia-taxi

Levy, A. (2020). 'Three things to think about in regards to Coronavirus'.25 April 2020:https://medium.com/@ ladi1010/three-things-to-think-about-in-regards-tocoronavirus-cc3b48c2d79a

Morrison, S. \& Carroll, A. (2020). 'Which Covid-19 Future Will We Choose?',Center for Strategic and International Studies (CSIS),01 April 2020: https://www.csis.org/analysis/which-covid-19-future-will-we-choose

Pettigrew, A.M. (1987). 'Context and Action in the Transformation of the Firm'. Journal of Management Studies, 24 (6), 649-69.

Rajagopalan, N. \&Spreitzer, G.M. (1997). 'Towards a Theory of Strategic Change: A Multi-lens Perspective and Integrative Framework. Academy of Management Review, 22(1), 48-79.

Razzetti, G. (2020). 'The Leadership Model Is Broken'. April 11, 2020. Liberationist: https://liberationist.org/the-leadership-model-is-broken/

Rossouw, D. (2020). 'This is not a time for a Moral Moratorium, but for Moral Imagination'in: The Ethics Institute Monthly Newsletter, 29 April 2020: https://www.tei.org. za/index.php/resources/articles/ethics-opinions/7963this-is-not-a-time-for-a-moral-moratorium-but-formoral-imagination

Shah, N. \&Irani, Z.\& Sharif, A. M. (2017). 'Big Data in an HR Context: Exploring Organizational Change Readiness, Employee Attitudes and Behaviors'. Journal of Business Research, 70, 366-378.

Van Vuuren, L. \& Vorster, P. (2020). 'Organisations with stronger ethics perform better. Here's why'. Apr 142020 in: fin24: https://www.fin24.com/Opinion/opinion-organisations-with-stronger-ethics-perform-better-hereswhy-20200414?fbclid=IwAR1y5OB2NFOLSlvgLikz8Ifx MatI7BmJnAN-Q2Eq7bO7bD0CbU6CDHdx_PM

Van Wart, M. \&Kapucu, N. (2011). 'Crisis Management Competencies: The Case of Emergency Managers in the USA'. Public Management Review, 13(4), 489-511.

Wilson, D. (1992). A Strategy of Change.London: Routledge.

Winkler Titus, N. (2020). 'How to manage forced unplanned change' in: HRFuture 2020, March Magazine, February 26, 2020, p. 36-39: https://www.hrfuture.net/online-magazines/2020/hrfuture-2020-march-magazine/

Zaidi,L.(2019), 'TheOnly ThreeTrends ThatMatter',03Jan 2019: https://medium.com/predict/the-only-three-trends-thatmatter-ee705e8ff9ce 